\title{
Mitochondrial Actions for Fat Browning and Energy Expenditure in White Adipose Tissue
}

\author{
de Andrade $\mathrm{PBM}^{*}$, Bolsoni-Lopes $\mathrm{A}^{3}$ and Alonso-Vale $\mathrm{MIC}^{2}$
}

${ }^{1}$ Interdisciplinary Program in Health Sciences, Institute of Physical Activity Sciences and Sport, Cruzeiro do Sul University, Sao Paulo, Brazil

${ }^{2}$ Department of Biological Sciences, Institute of Environmental Sciences, Chemical and Pharmaceutical, Federal University of São Paulo, Diadema, Brazil

${ }^{3}$ Department of Physiology and Biophysics, Institute of Biomedical Sciences 1, University of Sao Paulo, Sao Paulo, Brazil

${ }^{*}$ Corresponding author: de Andrade PBM, Institute of Physical Activity Sciences and Sport, Cruzeiro do Sul University, 868, Rua Galvão Bueno St, Sao Paulo, Brazil 01506-000, Fax: +55 1133853103 , Tel: +55 11 970941123, E-mail: paula.bmandrade@gmail.com

Citation: de Andrade PBM, Bolsoni-Lopes A, Alonso-Vale MIC (2016) Mitochondrial Actions for Fat Browning and Energy Expenditure in White Adipose Tissue. J Obes Overweig 2(2): 201. doi: 10.15744/2455-7633.2.201

Received Date: November 07, 2015 Accepted Date: May 24, 2016 Published Date: May 26, 2016

\begin{abstract}
White adipose tissue (WAT) is an endocrine organ with crucial role in the development of obesity and related diseases. White adipocytes have less mitochondria than brown adipocytes; nevertheless, there is an increasing body of evidence showing that mitochondrial parameters play a relevant role in WAT physiology, such as proliferation, differentiation and triacylglycerol storage levels. These parameters comprise mitochondria turnover, oxidative capacity, uncoupling, reactive oxygen species levels and oxygen consumption. In addition, the existence of beige (brown in white) adipose tissue and the transdifferatiation of WAT in brown adipose tissue are intrinsically related to mitochondria activity. Herein we highlight that the concerted action of stimulated lipolysis, mitochondrial oxidative metabolism and uncoupling (futile cycle) can enhance WAT energy expenditure. We consider WAT mitochondrial function a promising target for the development of therapies tackling lipotoxicity, obesity and related diseases.
\end{abstract}

Keywords: Obesity; Oxidation; Respiration; Metabolism; Fatty acid; Uncoupling; Browning; Mitophagy

List of Abbreviations: BAT: Brown adipose tissue; ETC: Electron transport chain; ERRa: Estrogen-related receptor alpha; FA: Fatty acids; FAO: Fatty acid $\beta$-oxidation; FFA: Free fatty acids; FGF21: Fibroblast growth factor 21; Dio2: Iodothyronine 5'-deiodinase; IL: Interleukin; MCP1: Monocyte chemotactic protein-1; MIRO: Mitochondrial rho GTPase; OXPHOS: Oxidative phosphorylation; PPAR: Peroxisome proliferator- activated receptor; PGC1: Peroxisome proliferator- activated receptor- $\gamma$ coactivator 1; Prdm16: PRD1- BF1RIZ1 homologous domain containing 16, ROS: Reactive oxygen species; TAG: Triacylglycerides; UCP1: Uncoupling protein 1; VDAC1: Voltage-dependent anion-selective channel protein 1; WAT: White adipose tissue.

\section{Obesity, a global issue}

Obesity can be defined as the disruption in the balance between fuel intake and energy expenditure in favor of energy conservation. Together with type 2 diabetes (T2DM), these are the two of the most prevalent diseases affecting modern societies, arising mostly by changes in eating habits and a sedentary lifestyle associated with poorly known genetic determinants. Obesity predisposes to the so-called metabolic syndrome, which includes inflammation, hypertension, T2DM and cardiovascular diseases [1]. Obesity is imposing an increasingly heavy burden on the world's population in rich and poor nations alike, with almost 30 percent of people globally now either obese (BMI $\geq 30$ ) or overweight (BMI $\geq 25)$ [2]. In fact, the number of overweight and obese people rose from 857 million in 1980 to 2.1 billion in 2013 [2]. Recently, obesity and metabolic syndrome were associated with mitochondrial dysfunction and deranged regulation of metabolic genes [3]. Interestingly, mitochondria of obese individuals seem to be different from those of lean individuals. Mitochondria from obese individuals display lower energy-generating capacity, less defined inner membranes and reduced fatty acid oxidation (FAO) [4]. 


\section{White Adipose Tissue (WAT)}

White adipose tissue (WAT) is the main tissue linked to obesity. WAT represents around 10\% of total body weight in lean adults and more than $50 \%$ in obese individuals [5]. WAT is composed of mature adipocytes and the stromal-vascular fraction that contains preadipose cells (or adipoblasts), fibroblasts, immune cells, and blood vessel-associated cells [6]. A single and large lipid droplet occupies most of the white adipocyte volume and WAT copes with obesity either expanding (hypertrophy) or recruiting new cells (hyperplasia) [7]. WAT secretes an array of peptide hormones called adipokines (including leptin and adiponectin), which regulate neurological activities such as appetite and behavior, metabolic activities of peripheral tissues [8] and produce several pro-inflammatory cytokines, such as tumor necrosis factor alpha (TNF- $\alpha$ ), interleukin 6 (IL-6), interleukin 1 (IL-1), resistin and monocyte chemotactic protein-1 (MCP1), with endocrine, paracrine and autocrine effects [9-15]. Visceral adipocytes produce more pro-inflammatory cytokines, while subcutaneous adipocytes are the main source of leptin and adiponectin [16]. WAT deposits present distinguished morphologic and metabolic activities, depending on their anatomical position, diameter and number of cells, hormone sensitivity, innervation, vascularity and mitochondria content [17-19].

For decades, WAT was regarded as a fat storage tissue where mitochondrial content and function were largely ignored. Nowadays, WAT is considered as an endocrine organ and mitochondria are considered to play an important role in WAT physiology.

\section{Mitochondria}

There are hundreds to thousands mitochondria in most eukaryotic cells. Their cellular distribution and localization are not homogeneous as they contemplate local energy demand [20-22]. Moreover, mitochondria are dynamic organelles and their morphology varies according to fusion and fission events of mitochondrial membranes [23]. Mitochondria are responsible for most of cellular adenosine triphosphate (ATP) generation, cellular respiration, oxidative stress regulation, calcium buffering and cell death [20,24]. Noteworthy, the orchestration of food intake, digestion, and processing is designed primarily to supply substrates destined for mitochondrial oxidation [24].

Mitochondria impairment is related to aging [25,26] and to a series of pathologies. The main sources of known mitochondriarelated diseases comprise electron transport chain (ETC) malfunction, impaired ATP generation, imbalance between reactive oxygen species (ROS) generation and sequestration, mutations in the nuclear and mitochondrial genomes and unbalanced mitochondrial turnover [26-28]. These conditions include hypercholesterolemia, hypertriacylglyceridemia [29], hepatic cytolysis and steatosis [30], myoclonic epilepsy with ragged-red fibers (MERFF), mitochondrial encephalomyopathy, lactic acidosis, and stroke-like syndrome (MELAS), mitochondrial inherited diabetes and deafness (MIDD) and T2DM [20,26,27]. Mitochondria dysfunction due to mitochondrial DNA (mtDNA) mutations and reduced oxidative metabolism is also related to various types of cancer, including breast cancer [31-33]. Neurons have a high density of mitochondria and, consequently, they rely heavily on mitochondrial parameters. Indeed, neurodegenerative diseases including Alzheimer, Parkinson, Huntington disease and Amyotrophic Lateral Sclerosis can be triggered by mtDNA defects, oxidative stress and mitochondria-induced cell death [28,3436].

In the last 15 years some promising therapies were applied in clinical trials carried out with subjects presenting mitochondrial diseases [37,38]. The results are still incipient but valuable in the pursuit of tailoring therapies to treat diseases of mitochondrial origin, which currently have no cure.

\section{Overview of Mitochondrial Relevance in White Adipocytes}

Mitochondrial biogenesis and metabolism are implicated in various processes of WAT physiology, such as pre-adipocytes proliferation, adipogenesis, carbohydrate and lipid metabolism, adipocyte de-differentiation, triacylglycerides (TAG) accumulation and acquirement of brown adipose tissue-like characteristics [17,18,39-44]. In fact, adipocyte mitochondria provide key intermediates for TAG synthesis and oxidize fatty acids released from lipolysis, providing ATP to meet energetic demand during starvation [45].

Recent data from mice studies show that inguinal adipocytes have higher mitochondria content when compared to epididymal adipocytes [46]. Moreover, they show that inguinal adipocytes have higher respiratory capacity attributable to higher mitochondrial respiratory chain content. On the contrary, it was shown that rat epididymal adipocytes are richer in mitochondria than inguinal adipocytes [47]. Therefore, it is not clear which adipocyte depot has more mitochondria. The relevance of uneven distribution of mitochondria content and function in distinct WAT depots would reflect in higher or lower bioenergetics of these depots. Fluctuations in bioenergetics would imply in alterations of ATP levels, oxidative stress, fatty acid synthesis and other relevant parameters of WAT physiology during proliferation and differentiation. These alterations would result in distinct lipolytic rate and TAG accumulation. 
Mitochondria function is also implied in WAT pathophysiology, particularly in obesity and related diseases, like T2DM. For instance, WAT mitochondrial content is relatively low in genetically obese and insulin-resistant mice [48]. This occurs because low cellular mitochondria content probably results in reduced oxidative capacity and more TAG accumulation, contributing to insulin resistance and obesity. Indeed, preadipocytes from the clonal cell line 3T3-L1 exposed to inhibitors of mitochondrial oxidative phosphorylation showed impaired respiration and TAG accumulation [19].

Mitochondria disruption in adipocyte pathways contributes vastly to the development of insulin resistance [45]. 3T3-L1 adipocytes exposed to the insulin sensitizer rosiglitazone, to $\beta 3$-adrenergic receptor activation and to the combined use of R- $\alpha$-lipoic acid and acetyl-L-carnitine displayed enhanced mitochondrial population, augmentation of the expression of several mitochondrial proteins and augmented FAO [49-51]. These findings were later proven in vivo by the use of white adipocytes from ob/ob mice treated with rosiglitazone that presented augmented mitochondrial mass, markedly enhanced oxygen consumption and significantly increased palmitate oxidation $[17,19,52]$. Moreover, dietary restriction of mice fed a high fat diet led to the upregulation of genes involved in lipid metabolism and mitochondrial function, activating WAT mitochondria and serum adiponectin levels, which are correlated to the enhancement of insulin sensitivity [53].

\section{Mitochondrial Parameters Involved in Adipogenesis and Oxidative Metabolism}

WAT adipogenesis (differentiation of preadipocytes into mature adipocytes) occurs as a result of a transcriptional cascade involving the tightly regulated induction of several transcription factors [54,55]. Adipogenesis is a high energy-demanding process that relies on mitochondrial biogenesis and functions that, in turn, provides ATP and intermediates for FA synthesis and TAG storage. Therefore, the relevance of mitochondria function during adipogenesis can be justified not only by the fact that mitochondriagenerated ATP fills the raised energetic demand of cellular differentiation, but also because mitochondria provide key substrates necessary to support the massive lipogenesis during adipogenesis. These substrates include acetyl-CoA and glycerol3-phosphate, essential for fatty acid synthesis and esterification [8]. There are many evidences indicating that mitochondrial biogenesis and adipogenesis occur simultaneously. One of the evidences is the fact that there is a 20-30-fold increase in abundance of mitochondrial proteins expression in the early stages of adipogenesis of 3T3-L1 cells [49].

Mitochondrial Prohibitins: It is worth mentioning the emerging roles of the mitochondrial membrane proteins prohibitins (PHBs) in adipocyte physiology. PHBs are highly conserved proteins located in the mitochondria, nucleus and plasma membrane of many cell types implicated in the modulation of longevity, cellular metabolism, mitochondria function, oxidative stress and adipogenesis [56-58]. There is a mitochondrial prohibitin complex located in the inner mitochondrial membrane composed of the subunits prohibitin-1 (PHB1) and prohibitin-2 (PHB2), which bind to each other forming an interdependent ring-like macromolecular structure [58]. This complex positively modulates mitochondrial respiration, mitochondrial genome, mitochondrial assembly and ROS generation [56,57]. An interesting study in yeast reveals that PHB complex controls mitochondrial inner membrane organization and integrity by acting as protein chaperones and lipid scaffolds [59]. In fact, PHBs knockdown may trigger cytochromec-cardiolipin complex dissociation and further cytochrome c release, increasing cellular susceptibility to apoptosis [57]. Specific PHB2 knockdown also leads to apoptosis by inducing the loss of optic atrophy 1 (OPA1), which is required for mitochondria fusion and cristae integrity. The opposite, PHB overexpression, is supposed to protect against apoptosis [57].

Not only PHBs levels are raised during mitochondrial biogenesis but also during 3T3-L1 adipogenesis. In fact, the levels of both PHB1 and PHB2 are significantly increased during adipogenesis of 3T3-L1 preadipocytes, especially in mitochondria [60]. PHBs inhibition was shown to impair adipogenesis and mitochondrial function both in 3T3-L1 cells and in human adipose-derived stem cells (ASC) [56,60]. In clonal 3T3-L1 cells PHBs silencing reduced mtDNA copy number, impaired mitochondrial function and resulted in mitochondrial fragmentation. This, in turn, led to elevated ROS generation and adipogenic reduction combined with reduced expression of adipogenic markers (C/EBPb, PPAR $\gamma$ and aP2) and less lipid accumulation [60]. These findings were corroborated in the studies with human ASC treated with micro RNAs (miR-27a,b) targeting and silencing PHBs, which resulted in reduced PPAR $\gamma$ levels and less adipogenesis [56].

Concerning mature adipocytes, a study revealed that 3T3-L1 adipocytes treated with isoproterenol markedly raised both lipolysis, as expected, but also increased PHB expression [61]. On the contrary, in a mouse model overexpressing PHB in adipocytes via $a P 2$ promoter (Mito-Ob mouse), it was observed that $\mathrm{PHB}$ overexpression led to mitochondrial biogenesis upregulation but also to obesity [62]. Curiously, visceral fat augmentation was more pronounced in female Mito-Ob and brown fat was more increased in male Mito-Ob mouse [62]. This obese phenotype could be explained by the fact that PHB1 may inhibit pyruvate carboxylase (PC) and, as a consequence, diminishes insulin-stimulated oxidation of glucose and fatty acid in mouse adipocytes [63]. PC inhibition would lead to oxaloacetate depletion and tricarboxylic acid cycle impairment, inhibiting cataplerosis and glyceroneogenesis (lipid accumulation). Further studies of PHBs overexpression have to be carried out to confirm these controversial findings between cellular and mouse models. 
Based on the PHB silencing studies we conclude that PHB inhibition leads to respiratory chain deficiency, defective mtDNA, excessive ROS generation and apoptosis stimulation. Therefore we conclude that PHBs are key proteins that promote mitochondrial biogenesis, inner mitochondrial membrane stabilization and positive modulation of oxidative phosphorylation and ROS. This, in turn, results in the proper function of mitochondrial respiration, ATP synthesis and Krebs cycle, together with the prevention of apoptosis and oxidative stress. All in all, the importance of PHBs in adipogenesis is another evidence of mitochondrial relevance in adipocyte physiology. Nevertheless, more studies are required to confirm the lipolytic role of PHBs in mature adipocytes.

PGC1- $\boldsymbol{\alpha}$ and PGC1- $\beta$ : Peroxisome proliferator-activated receptor- $\gamma$ coactivator 1-alpha (PGC1- $\alpha$ ) is a member of a family of transcription co-activators that plays a central role in the regulation of cellular energy metabolism, mainly via the promotion of oxidative metabolism and mitochondrial biogenesis [19,64]. PGC1-a regulates central features of highly metabolic active tissues, such as BAT, heart, skeletal muscle, liver, testis and the central nervous system (CNS), such as thermogenesis, contractile force, oxidative fiber types, gluconeogenesis, beta-oxidation and apoptosis $[65,66]$. In brown fat, PGC1- $\alpha$ activation by peroxisome proliferator-activated receptor alpha (PPAR $\alpha$ ) provides a molecular mechanism for concerted induction of thermogenic and fatty acid oxidation (FAO) genes [67]. In WAT, PGC1- $\alpha$ is at the crossroads of oxidative metabolism [68-70]. In white adipocytes, PGC1- $\alpha$ contributes to mitochondrial biogenesis and adipogenesis via activation of specific transcription factors involved in the expression of nuclear genes encoding mitochondrial proteins and/or adipogenic markers. These markers include CREB (cyclic AMP response element-binding protein), ERR $($ estrogen-related receptor alpha), and peroxisome proliferator-activated receptor gamma (PPAR $\gamma)$, among others [17]. Studies conducted with rat WAT indicate that PGC1- $\alpha$ may help WAT cells withstand high energetic demands during physiological stress [19,71]. Besides, there is increasing evidence showing that PGC1- $\alpha$ plays an important role in obesity, diabetes and cardiomyopathy, making it an attractive target for drug development in the treatment of these diseases [64,72]. PGC-1 $\alpha$ is intimately involved in adaptive thermogenesis, skeletal muscle fiber type switching, glucose/ fatty acid metabolism, and heart development. Among these varied biological responses, a common mechanism of action appears to be the promotion of oxidative metabolism accompanying the stimulation of mitochondria biogenesis. The promotion of fatty acid oxidative metabolism leads to a reduction of fat accumulation in muscle, which, in turn, increases insulin sensitivity and the glucose uptake by insulin-sensitive tissues [64].

PGC1- $\beta$ is encoded by the Ppargclb gene and is preferentially expressed in tissues with relatively high mitochondrial content, including heart, slow skeletal muscle and BAT [3]. PGC1- $\beta$ knockout mice display an altered expression in a large number of nuclear-encoded genes that regulate mitochondria energy metabolism in multiple tissues and these mice are extremely sensitive to cold exposure and develop hepatic steatosis upon feeding with high fat diet $[69,73]$.

PGC1- $\beta$ function in WAT is largely unknown. It was observed that PGC1- $\beta$ overexpression in 3T3-L1 adipocytes raises insulin sensitivity, increases mitochondria biogenesis and mitochondrial function [73]. The effect of PPAR $\gamma$ agonists on PGC1- $\beta$ mRNA levels in 3T3-L1 adipocytes was tested and PPAR $\gamma$ ligands increased mRNA levels and steady state levels of PGC1- $\beta$ protein [74]. This study was done using short interfering RNA against PGC1 $\beta$ and demonstrated that this coregulator is required for TZDdependent increases in mitochondrial gene expression, oxygen consumption and palmitate oxidation in 3T3-L1 cells. Knockdown of PGC1- $\beta$ in 3T3-L1 cells did not alter adipogenesis, lipogenesis or glucose uptake [74]. Therefore, PPAR $\gamma$-induced PGC-1 $\beta$ expression has an effect on WAT mitochondrial activity, but not in fat storage. This finding is in line with a study done with PGC1 $\beta$-FAT-KO mice. In this study, PGC1 $\beta$ deletion did not alter fat accretion or white adipocyte size, since the expression of terminal markers of adipocyte differentiation or genes encoding for proteins involved in lipid synthesis were not differentially regulated in the WAT of PGC1 $\beta$-FAT-KO mice [75].

WAT PGC1- $\alpha$ transcript seems to be barely detectable and are present at lower levels than those of PGC1- $\beta$ in both differentiated 3T3L1 cells and mature WAT. Nevertheless, PGC1- $\alpha$ transcripts levels are higher in preadipocytes, suggesting that PGC1- $\alpha$ might play a more relevant role in preadipocytes proliferation and PGC1- $\beta$ might be more active in mature adipocytes [74]. Despite the fact that PGC1- $\alpha$ and PGC1- $\beta$ play similar roles in mitochondrial activity, their actions are only partially redundant $[69,73,74]$. PGC1- $\alpha$ and PCG1- $\beta$ might be important regulators of white adipocyte energy metabolism, especially regarding mitochondrial biogenesis and adaptive thermogenesis. Despite the fact that they are appointed as possible targets for the development of antiobesity drugs, more studies are required to clarify the plausible molecular mechanisms involved in the specific regulation of mitochondrial biogenesis markers, regulation of uncoupling proteins expression as well as their interaction with different types of nuclear receptors and transcriptions factors involved in the control of energy metabolism.

Mitochondrial Fatty Acid Oxidation and Uncoupling: During lipolysis, TAG undergoes lipases-driven hydrolysis ultimately releasing glycerol and unesterified FA (free fatty acids, FFA). WAT FFA has at least four fates: (i) reesterified inside WAT, (ii) used as substrate for mitochondria uncoupling, (iii) oxidized inside mitochondria (FAO) and (iv) released to circulation. Plasma FFA is used as energetic substrate by other tissues but can lead to lipotoxicity when in excess.

It is usually considered that FFA re-esterification is the major pathway to retain FA within the adipocyte, preventing excessive release of FFA from lipolysis to circulation [76,77]. 
It is important to state that, at cellular metabolism level, there are biochemical mechanisms that are dedicated to transform chemical energy into heat, increasing total body energy expenditure. These processes include uncoupling of the mitochondrial respiratory chain and substrate cycles (futile cycles), being simultaneous lipolysis and FFA re-esterification (FA cycle) a key substrate cycle for lipid metabolism regulation [78,79]. Uncoupling of the mitochondrial respiratory chain is mediated physiologically by uncoupling proteins (UCPs). UCPs are mitochondrial inner membrane proteins present in plants and mammals, including humans. There are five known isoforms of mammalian UCPs: UCP1 (or thermogenin) is expressed in BAT and dissipates the proton gradient to generate heat (non-shivering thermogenesis), UCP2 is ubiquitously expressed at varying levels in different tissues, including WAT and brain, UCP3 is expressed in skeletal muscle and heart, UCP4 and 5 are predominant in neural tissues [80]. UCPs dissipate part of the proton gradient across the inner mitochondrial membrane resulting in diminished ATP synthesis and, as recently shown; reducing ROS levels [80]. Interestingly, UCP2 is considered to increase adiponectin gene expression and WAT adipogenesis through the modulation of mitochondrial ROS production $[81,82]$.

Mitochondrial uncoupling (UCPs) and FAO contribute to reduce FFA efflux from adipocytes [83,84], moreover, mitochondria provide glyceroneogenic substrates that contribute to FA re-esterification. Indeed, mitochondria impairment induces TAG accumulation in 3T3-L1 cells via diminished FAO and augmented glucose conversion into TAG [85]. Yet, there are evidences suggesting that FAO is a minor pathway when compared to FA re-esterification in white adipocytes $[76,77,86]$. Mitochondrial uncoupling induction represents a maximal FA consumption rate of 3.5\% when compared to the rate of FA release from lipolysis [86]. However, taking into account that WAT corresponds to more than $50 \%$ of total body weight in obese individuals, this metabolic pathway may represent a significant physiological mechanism to handle the excess of FFA in obesity in mid-long term. Moreover, FA redistribution from peripheral tissue to the liver is a slow process that takes several years, indicating that low FAO rate should suffice $[83,84]$.

In our opinion, FA re-esterification might be indeed the major and most immediate pathway to retain FA inside adipocytes, but the contribution of WAT FAO and uncoupling cannot be neglected in WAT physiology. Once inside mitochondria, FA cycling via UCPs (uncoupling) contributes to keep FAs longer inside the mitochondria, which increases their availability to be oxidized and prevents exacerbated TAG storage. In a long-term basis, FAO stimulation would probably help to diminish insulin resistance in peripheral tissues (less ectopic fat accumulation) and boost metabolic rate and weight loss. Indeed, many evidences corroborate that efficient mitochondrial WAT FAO may increase respiratory capacity, reduce adipocyte size, enhance lipolysis and reduce lipotoxicity $[17,87,88]$. Unpublished data from our group show that an increase on mitochondrial WAT FAO (30\%) and WAT oxygen consumption (10\%) due to the action of unsaturated fatty acid treatment (palmitoleic acid) occurs simultaneously to an augmentation on lipolysis (3,5-fold). This paper is under submission. A recent study with human twins showed that adiposity is correlated with downshifting of fatty acid oxidation and that, indeed, mitochondrial biogenesis, oxidative metabolic pathways and OXPHOS proteins in subcutaneous adipose tissue are down regulated in acquired obesity [89]. Thus, WAT FAO stimulation can be considered a target to develop therapies for prevention and treatment of obesity, insulin resistance and related pathologies via energy expenditure augmentation and fat loss.

Potential modulators of WAT FAO: Increased lipolysis may result in a shift within adipocytes towards increased FA utilization and energy expenditure, protecting against overweight and obesity [90]. We agree with this hypothesis and suggest that, in combination with lipolysis, regulated mitochondrial uncoupling and FAO are crucial for the improvement of whole-body sensitivity to insulin due to less FFA release to circulation. Therefore, compounds with the potential to boost lipolysis, WAT mitochondrial FAO and uncoupling capacity should be considered to be employed in future clinical trials.

It was proposed that pharmacological WAT protein kinase $\mathrm{C} \beta(\mathrm{PKC} \beta)$ inhibition led to body fat loss under normal caloric intake due to increased WAT mitochondrial biogenesis, PGC1- $\alpha$ and mitochondrial FAO increase [70]. In addition, systemic chronic pharmacological AMP-kinase (AMPK) activation might reduce adiposity via the enhancement of WAT oxidative machinery [91]. It was also proposed that allosteric activation of AMPK in white adipocytes could stimulate FAO, enhance PGC1- $\alpha$ expression and enhance mitochondrial biogenesis [92]. Another proposal was that the chronic pharmacological $\beta 3$-adrenergic receptor activation in white adipocytes, leading to a transitory inflammatory response followed by mitochondrial biogenesis, would increase the expression of genes involved in both FAO and white to brown adipocyte transdifferentiation [50,93-95]. PPARa is also a positive regulator of thermogenic components [67,96-98] and PGC1- $\alpha$ and PPAR $\alpha$ target genes are involved in FA catabolism, including FA cellular uptake, mitochondrial and peroxisomal $\beta$-oxidation [99].

\section{MitoNEET inhibition}

Another candidate to modulate WAT FA handling is MitoNEET. MitoNEET (CDGSH iron-sulfur domain-containing protein 1 or CISD1) is a protein anchored in the outer mitochondria membrane of rodents and human brain, heart, skeletal muscle, liver and adipocytes that contains Fe-S clusters which regulate mitochondrial matrix ion levels and oxidative capacity [100]. MitoNEET exists in low levels in preadipocytes and its expression increases exponentially in differentiated adipocytes [100]. Surprisingly, MitoNEET overexpression at physiological levels in mice WAT with a leptin-deficient $o b / o b$ background (MitoN-Tg ob/ob) boosts 
lipid uptake and storage reduces fat uptake in the liver and preserves insulin sensitivity due to augmented adiponectin production [5]. This mouse model resembles the metabolic healthy obese (MHO) state. In this context, $\beta$-oxidation is inhibited, mitochondrial membrane potential is reduced and ROS generation is diminished. Conversely, reduction of MitoNEET expression results in augmented mitochondria respiratory capacity, less weight gain on high fat diet (HFD) but elevated oxidative stress and higher glucose intolerance. The effect of MitoNEET overexpression in a non-ob/ob phenotype was also observed (MitoN-Tg mouse) [45]. MitoN-Tg mice received HFD for 15 weeks and, up to week 12; the weight of MitoN-Tg mice was not different from control mice. After week 12, there was healthy WAT expansion, without inflammation nor fibrosis, high sWAT vascularization and detection of small adipocytes [45]. Simultaneously, a browning signature program was activated in MitoN-Tg sWAT, including UCP1 and PGC1- $\alpha$ upregulation. This browning phenotype was lost by week 13 [45].

Ultimately, MitoNEET exerts a positive impact on WAT expansion and whole-body lipid and carbohydrate homeostasis by altering mitochondrial matrix iron metabolism [45]. Despite $\beta$-oxidation inhibition and ETC impairment, mitoNEET enriched fat pads result in a MHO phenotype and may prevent diabetes via improvement of insulin sensitivity. In fact, MitoNEET is a target of the antidiabetic drug pioglitazone via blockage of thiol-mediated reduction of its Fe-S clusters and it boosts adiponection secretion (MitoNEET-adiponectin axis) [95]. MitoNEET overexpression inhibits $\beta$-oxidation and ETC function, which is not desirable during pre-adipocyte proliferation that is probably the reason why mitoNEET is present in low levels in preadipocytes [100]. But, in obesity, MitoNEET controlled overexpression can be considered a promising target to improve this condition via healthy WAT expansion.

\section{Liver receptor $\mathrm{X}$}

Recently, a WAT knockout mouse for liver receptor X (ATaKO mouse) was generated and it presented more weight gain and fat mass on a high fat diet compared with wild-type controls, as a result of the decrease in WAT lipolytic and oxidative capacities [87]. Accordingly, liver receptor $\mathrm{X}$ activation in vivo and in vitro led to decreased adipocyte size in WAT and increased glycerol release from primary adipocytes, respectively, with a concomitant increase in oxygen consumption rates [87]. Therefore, liver receptor X is another candidate to modulate WAT energy expenditure.

\section{Unsaturated Fatty acids}

Some unsaturated FA are relevant candidates to improve WAT lipolysis, FAO and respiratory rate. Marine-derived polyunsaturated fatty acids eicosapentaenoic (EPA, omega 3) and docosahexaenoic (DHA, omega 3) have an antilipogenic effect and preferentially upregulate expression of genes for mitochondrial proteins, including PGC1- $\alpha$ and nuclear respiratory factor-1 (Nrf1), increasing mitochondrial FAO while depressing lipogenesis in abdominal fat [88]. Besides, we have recently shown that the monounsaturated FA palmitoleic acid (omega 7) controls important metabolic processes in white adipose tissue, enhancing adipocyte lipolysis and the content of the major lipases: adipose triglyceride lipase (ATGL) and hormone-sensitive lipase (HSL), via a PPARa-dependent mechanism [101,102]. Palmitoleic acid also improves WAT FAO and oxygen consumption (unpublished data).

Table 1 summarizes some candidates to enhance WAT oxidative metabolism via fatty acid oxidation, uncoupling and lipolysis.

\begin{tabular}{|c|c|c|}
\hline Event & Target & Activation \\
\hline \multirow{4}{*}{ FAO } & PGC1- $\alpha, \beta$ activation & $\begin{array}{l}\text { PPARa [67], AMPK [95], [103], SIRT1 [104], } \\
\text { Nebivolol [68,105] }\end{array}$ \\
\hline & $\beta 3$-adrenergic receptor activation & $\begin{array}{c}\text { Mirabegron [113], CL 316,243 [93,106] } \\
\text { Nebivolol [105] }\end{array}$ \\
\hline & $\mathrm{PKC} \beta$ inhibition & Ruboxistaurin [106] \\
\hline & MitoNEET inhibition & downregulation $[5,45]$ \\
\hline \multirow[b]{2}{*}{ FAO and Lipolysis } & PPAR- $\alpha$ activation & $\begin{array}{c}\text { FAs and FA-derived compounds }[88,101,102] \\
\text { Adrenergic stimuli }[93,107]\end{array}$ \\
\hline & LXR- $\alpha$ activation & $\begin{array}{c}\text { Endogenous oxysterols [108] } \\
\text { Nonsteroidal LXR agonists T0901317, GW3965 } \\
\text { [109] }\end{array}$ \\
\hline Uncoupling & UCP1 expression & $\begin{array}{c}\text { 3,5,3'-Triiodothyronine (T3) [110] } \\
\text { Norepinephrine }[110] \\
\text { Cold exposure [111], PPAR- } \alpha, \beta, \text { FFA }[45,77] \\
\text { MitoNEET overexpression }[45]\end{array}$ \\
\hline
\end{tabular}

Table 1: Targets to enhance WAT oxidative metabolism via Fatty Acid Oxidation, uncoupling and lipolysis stimulation Abbreviations: AMP: Adenosine monophosphate; AMPK: AMP-dependent protein kinase; AMPKK: AMP-Activated Protein Kinase Kinase; FA: Fatty acid; FAO: Fatty acid oxidation; FFA: Free fatty acid; LRX-a: Liver receptor alpha; MitoNEET: CDGSH iron-sulfur domain-containing protein 1; PGC1- $\alpha$ : Peroxisome proliferator- activated receptor- $\gamma$ coactivator 1-alpha; PPAR- $\alpha$ : Peroxisome proliferator- activated receptor- $\alpha$; SIRT1: Sirtuin 1; UCP1: Uncoupling protein 1 
Some of these compounds were evaluated in human clinical trials, such as Mirabegron, Nebivolol and Ruboxistaurin (Table 2). In particular, Mirabegron is a $\beta 3$-adrenoreceptor agonist currently approved to treat overactive bladder. Phase II studies and four large-scale phase III multinational randomized, controlled trials have supported the efficacy of mirabegron in the clinical trial of patients with overactive bladder during 12 weeks and also for 12 months [112]. Surprinsingly, Mirabegron has been assigned to raise resting metabolic rate and BAT thermogenesis [113]. In this study, male humans who received $200 \mathrm{mg}$ oral mirabegron presented higher BAT metabolic activity (measured via (18)F-fluorodeoxyglucose (18)F-FDG) using positron emission tomography (PET) combined with computed tomography $(\mathrm{CT}))$ and raised resting metabolic rate $(\mathrm{RMR})$ by $203 \pm 40 \mathrm{kcal} / \mathrm{day}(+13 \% ; \mathrm{p}=0.001)$.

\begin{tabular}{|c|c|c|c|}
\hline Compound & Current Clinical Use & Mechanism & Recent Clinical Trials \\
\hline Mirabegron & $\begin{array}{c}\text { B3-AR agonist currently approved to } \\
\text { treat overactive bladder }\end{array}$ & $\begin{array}{c}\text { Augmentation of RMR (resting metabolic } \\
\text { rate), stimulate, BAT thermogenesis. }\end{array}$ & [113] \\
\hline Ruboxistaurin & $\begin{array}{c}\text { Diabetic peripheral neuropathy } \\
\text { treatment }\end{array}$ & specific inhibition of PKC beta & {$[114]$} \\
\hline Nebivolol & $\begin{array}{c}\text { To treat hypertension, (acts as } \\
\text { vasodilator) }\end{array}$ & $\begin{array}{c}\text { Thermogenic program activation, } \\
\text { lipolysis augmentation, adiponectin rise }\end{array}$ & {$[115-117]$} \\
\hline
\end{tabular}

Table 2: Recent clinical trials employing compounds from table1

\section{Mitochondria Dynamics, Autophagy and Cell Death}

\section{Mitochondria Dynamics}

Cellular homeostasis is modulated by mitochondria bioenergetics but also by mitochondria shape, location, turnover and dynamics. As a matter of fact, mitochondria are dynamic organelles that undergo constant and regulated fission and fusion, being morphologically classified as networked, fragmented and swollen $[23,25,82,118]$. Intracellular events that regulate fusion and fission include oxidative stress, membrane potential, mtDNA quality and apoptosis [22]. The most relevant proteins related to mitochondria fusion regulation in mammals are mitofusin1 (MFN1), mitofusin 2 (MFN2) and optic atrophy 1 (OPA1). MFN1, MFN2 are regulators of mitochondrial outer membrane fusion and OPA1 is anchored to the mitochondrial inner membrane, promoting inner membrane fusion [22]. Cytosolic dynamin-related protein 1 (DRP1) and outer-membrane-associated FIS1 regulate mitochondrial fission ([23]. In fact, fission is a sign for mitochondrial degradation and removal under physiological and pathophysiological conditions [22].

Adipogenesis is partially regulated by mitochondrial fusion and fission. A study demonstrates that mitochondria morphology is altered from a continuous reticulum to fragmented and/or punctate structures in 3T3-L1 pre-adipocytes during differentiation, concomitant with TAG accumulation [118]. In addition, there is WAT mitochondria redistribution around the lipid droplets, uncoupling of mitochondrial respiration and increased expression of genes involved in FAO, suggesting that mitochondrial network and metabolism are altered during the first days of adipogenesis in 3T3-L1 cells [82]. The increase observed in the levels of proteins involved with mitochondrial network, namely Drp1 and MFN2, during 3T3-L1 differentiation provided a molecular support for the relevance of mitochondria dynamics in adipogenesis [82]. A recent study claims that mitochondria fusion is a good indication of energy expenditure augmentation and lower insulin resistance in adipocytes [119]. This was indicated by upregulation of Opa1, Mfn1 and Mfn2 genes [119]. Therefore, mitochondria remodeling during adipogenesis probably occurs to attend the energetic demand of lipid droplets formation. Afterwards, excessive mitochondria are eliminated to give place to a single large lipid droplet that occupies most of cytosolic volume in fully differentiated adipocytes.

\section{Mitochondrial Permeability Transition Pore}

Mitochondria are important regulators of cell death and respond to distinct stress signals, including loss of growth factors, hypoxia, oxidative stress, and DNA damage. The initiation of a cell death program is mediated by permeabilization of the outer mitochondrial membrane (apoptosis) or by the opening of the mitochondrial permeability transition pore (mPTP) in the inner mitochondrial membrane [120]. The mPTP is a high conductance pore that establishes a mitochondrial membrane permeability transition leading to the disruption of the mitochondrial membrane potential, mitochondria swelling and rupture of the outer mitochondrial membrane, ultimately leading to mitochondria autophagy, apoptosis or necrosis [121-123]. One of the triggers for mPTP opening is calcium overload. Once mPTP is opened, it mediates a catastrophic increase in the permeability of the inner mitochondrial membrane, collapses membrane potential, prevents ATP synthesis and results in cell death [28].

\section{Mitophagy}

Mitochondria autophagy (mitophagy) is an early repair mechanism that takes place before apoptosis or necrosis. During mitophagy dysfunctional mitochondria are selectively eliminated by autophagosomes for the sake of mitochondria function and host cell integrity [120]. Mitophagy probably avoids exchange of defective mtDNA and defective mitochondrial proteins during fusion and fission events in a mitochondria pool, preventing the spread of innate mitochondrial dysfunction. 
Mitophagy occurs via recruitment into isolation membranes, which seal and fuse with lysosomes for further degradation [124]. Mechanistically, upon loss of mitochondrial membrane potential the cytosolic protein Parkin rapidly translocates to mitochondria promoting ubiquitination of some mitochondrial proteins (VDAC1, MFN1, MFN2 and MIRO) inducing damaged mitochondrion removal by an autophagosome [120]. It seems that Parkin is the key molecule that recognizes defective mitochondria and selectively removes it reducing mitochondria mass in the cell. There are two putative pathways to recruit Parkin to mitochondria: (1) via PINK1 (2) via NIX and BNIP3. After, mitochondria are removed with the aid of the protein p62 (adaptor) or Bnip3 and Nix (receptors), which interact with microtubule-associated protein 1A/1B-light chain 3 (LC3) on the autophagosome [120]. Mitophagy regulation may involve not only the autophagic machinery, but also proteins associated with mitochondria dynamics (fusion and fission machinery) and morphology [22]. The exact mechanism of these pathways is under debate and has to be further clarified.

The existence of selective and nonselective autophagy was proposed [22]. Nonselective autophagy is the removal of organelles induced by starvation to provide recycled biomolecules to the cell, a cellular survival mechanism. On the other hand, selective organelle autophagy would take place under nonstarving conditions [22]. There is another category of autophagy named "Developmental Autophagy". In this kind of autophagy there is no discrimination between healthy and non-healthy mitochondria [22]. The hypothesis of developmental autophagy is that mitochondria would be eliminated to attend cellular energy demand and function, such as red blood cells. Indeed, mature mammals erythrocytes are deprived of mitochondria for several reasons, the most important being to avoid the generation of reactive oxygen species of mitochondrial origin. We infer that there are distinct sorts of mitochondria autophagy. They may vary according to the metabolic state of the cell (starved or non-starved), on the energetic demand of a certain cell type (muscular, cardiac, adipose, red blood cells) and, also, on the developmental phase of the cell (proliferation or differentiation). Regarding adipocytes we believe that, during adipocyte proliferation and differentiation, selective mitophagy is predominant and dysfunctional mitochondria are recognized and eliminated. Later, during the final stages of adipocyte formation, developmental mitophagy probably takes over and remove the amount of mitochondrial population necessary to attend the energetic needs of the mature cell, independent of mitochondria functionality. We propose the following classifications for mitophagy (Table 3).

\begin{tabular}{|c|c|c|}
\hline \multicolumn{2}{|c|}{ Mitochondria autophagy } \\
\hline $\begin{array}{c}\text { Mitophagy } \\
\text { Selective: quality control } \\
\text { removes dysfunctional mitochondria }\end{array}$ & Mediators & Metabolic condition \\
\hline $\begin{array}{c}\text { Developmental Autophagy } \\
\text { non-selective }\end{array}$ & Bnip3L, Atg7, Ulk1 & Nonstarving \\
\hline $\begin{array}{c}\text { Autophagy } \\
\text { non-selective }\end{array}$ & Drp1 phosphorylation & Starvation-induced \\
\hline
\end{tabular}

Table 3: Mitophagy classification

Mitophagy in white adipocytes: A unique aspect of pre-adipocyte differentiation into adipocyte is the removal of the bulk of the cytoplasmic contents, particularly the removal of excess mitochondria, and their substitution with a single, large lipid droplet that occupies most of the cytoplasmic space $[8,22,121]$. The inactivation of adipocyte mitophagy in vitro and in vivo results in post differentiated cells exhibiting atypical morphology, with many small lipid droplets and large numbers of mitochondria, rather than the single large lipid droplet and relatively few mitochondria observed in normal white adipocytes. Accordingly, the phenotype observed in mice with mitophagy-deficient adipose tissue, includes reduced adiposity, resistance to diet-induced obesity and increased insulin sensitivity. Nevertheless, more experiments are necessary to test whether WAT mitophagy inactivation (or mitochondria biogenesis activation) may prevent or treat obesity and insulin resistance $[8,13,125]$.

It has been demonstrated that when mitophagy is reduced or inactivated in adipocyte progenitor cells in vitro, these cells are not able to differentiate into white adipocytes [8]. Another evidence correlating mitophagy and WAT differentiation is that the number of mitochondria in fully differentiated mature adipocytes is markedly reduced when compared to primary mouse embryonic fibroblasts in early stage of differentiation [8]. Indeed, when white adipocytes reach the mature state, mitochondria are reduced in number via mitophagy and squashed around the lipid droplets [125]. The detailed mechanism explaining how mitophagy selectively eliminates some mitochondria ("quality control") and how mitophagy is regulated during adipogenesis remains unclear.

\section{Mitochondrial actions for fat browning}

\section{Brown Adipose Tissue (BAT)}

Adipose tissue is classified in two major types distributed throughout the body: white (WAT) and brown (BAT) adipose tissue [126]. Brown adipocytes are multilocular and contain fewer lipids than white adipocytes, but more mitochondria [11,127,128]. BAT is heavily innervated by sympathetic nerves and it is responsible for a major portion of cold-induced thermogenesis, dietinduced thermogenesis, modulation of body temperature, energy expenditure and adiposity [129-131]. The thermogenic ability of BAT is conferred by UCP1, a protein that dissipates the proton electrochemical gradient generated during respiration across the mitochondrial membrane as heat $[19,132,133]$. 
It was proposed that brown fat and skeletal muscle arise from a common progenitor in the dermamyotome expressing the transcription factor myf5, which does not give rise to white adipocytes $[18,134]$. The differentiation of brown preadipocytes into brown adipocytes is controlled by transforming growth factor- $\beta$ family proteins, such as bone morphogenetic protein (BMP)-7 and myostatin. In addition, C/EBP- $\beta$ and PR domain containing 16 (Prdm16) have been shown to act as key transcriptional factors in the differentiation of brown adipocytes [135].

The presence of metabolically active BAT in small rodents is already well established in the literature [128,136]. Surprisingly, metabolically active BAT has been also identified in adult humans' neck, cervical, supraclavicular, and paravertebral regions being functional and activated upon cold exposure [132,137-141]. In an attempt to establish the presence of metabolically active BAT in adult humans, some studies using fluorodeoxyglucose-positron emission tomography and computed tomography, (PET-CT), demonstrated that $7.5 \%$ women analyzed had significant BAT deposit, while only $3.1 \%$ of men contained significant BAT storage, demonstrating that BAT is more abundant in women than in men [132]. Yet, when volunteers were exposed to cold (19 $\left.{ }^{\circ} \mathrm{C}\right)$ for 2 hours and evaluated by the same test mentioned above, they demonstrated that approximately $53 \%$ of individuals between 25 and 35 years old had an increase in FDG uptake, while only $8 \%$ of individuals between 38 and 65 years presented this increase, indicating that older individuals present a reduction in the BAT activity [130]. Thus, brown adipose tissue (BAT) burns fat to produce heat when the body is exposed to cold and plays a role in energy metabolism.

Decreased BAT activity is associated with body fat accumulation and aging [133]. Moreover, there is an emerging hypothesis suggesting that BAT build up stimulation in obese individuals may help to lose weight [142-145]. Accordingly, mice without functional BAT are prone to obesity and T2DM [146]. Using a transgenic toxigene approach to create two lines of transgenic mice with primary deficiency of brown adipose tissue, it was demonstrated that after 16 days, both lines have decreased brown fat and installed obesity: in one line, brown fat subsequently regenerates and obesity resolves; in the other line, the deficiency persists and obesity, with its morbid complications, advances [147]. This study supports a critical role for BAT in the metabolic homeostasis of mice. In addition, it was recently demonstrated that cold-recruited BAT in adults is thermogenically active and it contributes to the reduction of body fat [148]. They examined the effects of repeated stimulation by cold and capsinoids (nonpungent capsaicin analogs) in healthy human subjects with low BAT activity. Acute cold exposure at $19{ }^{\circ} \mathrm{C}$ for 2 hours increased energy expenditure. Cold-induced increments of energy expenditure strongly correlated with BAT activity independently of age and fat-free mass. Daily 2-hour cold exposure at $17{ }^{\circ} \mathrm{C}$ for 6 weeks resulted in a parallel increase in BAT activity and cold-induced increments of energy expenditure and a concomitant decrease in body fat mass. Similarly, daily ingestion of capsinoids for 6 weeks increased cold-induced increments of energy expenditure. These results suggest that human BAT can be recruited even in individuals with decreased BAT activity. Others studies also showed that BMI and \% of body fat are inversely correlated with BAT activity, indeed indicating that obesity is associated with low BAT activity $[129,132,146]$.

\section{Brite adipocytes}

Mice BAT mitochondria are more similar to muscle mitochondria and WAT mitochondria express proteins associated with anabolic pathways and proteins involved in the degradation of xenobiotics [18]. Tang et al. [137] have proposed that WAT progenitors reside in the mural cell compartment of the adipose vasculature but not in the vasculature of other tissues. Tran et al. [149] have shown evidences that both white and brown fat depots (murine and human) have endothelial origin. However, there is not a clear-cut consensus concerning BAT and WAT genesis and more studies are required to clarify this issue.

Interestingly, there is a large body of evidences in the literature showing the existence of pockets of brown adipocytes developing within WAT, called beige or brite adipocytes. They do not seem to be derived from the same precursors that give rise to classical BAT, suggesting that white adipocytes (or their precursors) would be able to undergo some type of reprogramming of their gene expression program to become a "brown-like" cell $[49,52,138,139]$. Indeed, brite adipocytes are not proliferating classic brown adipocytes and they constitute a subset of adipocytes with a developmental origin and molecular characteristics that distinguish them as a separate class of cells [150]. Brite adipocytes have functional thermogenic genes (UCP1) but these cells are devoid of transcripts for the transcription factors associated with classic brown adipocytes (Zic1, Lhx8, Meox2, and Prdm16) or for myocyteassociated genes (myogenin and muscle-specific microRNAs) and they retain white fat characteristics (Hoxc9 expression) [150].

There are some hypotheses for occurrence of brite adipocytes. One is the existence of pockets of brown adipocytes developing within WAT. They do not seem to be derived from the same precursors that give rise to classical BAT, suggesting that white adipocytes (or precursors) would be able to undergo some type of reprogramming of their gene expression program to become a "brown-like" cell $[49,52,138,151]$. Another proposal suggests the existence of a pool of brite preadipocytes that differentiate into brite adipocytes (not active) that could be further activated by cold, beta-adrenergic stimuli or other factors [152]. Apparently, mice inguinal adipocyte depot has the highest propensity to recruit brite adipocytes upon chronic cold exposure [152].

A hot topicin adipocyte researchis the existence of possibility of turning white adipocytesintobrown adipocytes(transdifferentiation). WAT to BAT transdifferentiation, regarded as the promotion of brown features in white adipocytes (named brite adipocytes), may reduce lipid accumulation, prevent obesity and diabetes, induce thermogenesis and it has already been described in mice, rats and human adipocytes $[43,44,72,94,153-155]$. White adipocyte browning relies on mitochondria parameters, including PGC1- $\alpha$ and 
UCP1. For instance, chronic treatment of white adipocytes with rosiglitazone, a PPAR $\gamma$ agonist, promoted PGC-1a expression and mitochondriogenesis, as well as norepinephrine-augmentable UCP1 gene expression in these cells [150]. Below (9.3) we describe some WAT browning pathways and mitochondrial contribution, mainly via uncoupling and oxidation.

\section{WAT browning factors}

Brown adipogenesis requires the master regulator zinc finger protein (Prdm16) and the transcriptional coactivator peroxisome proliferator-activated receptor-gamma coactivator 1 alpha (PGC1- $\alpha$ ). Prdm16 is a factor selectively expressed in BAT that activates a broad program of brown fat differentiation when expressed in cultured white fat preadipocytes or in white fat depots in vivo $[126,134]$. In fact, Prdm16 is highly expressed not only in BAT but also in subcutaneous white adipocytes. Prdm16 boosts the increase of mitochondrial genes expression, greater density of mitochondria and raised UCP1 expression, ultimately stimulating mitochondria uncoupling and energy expenditure [126].

Irisin, a new polypeptide hormone activated by exercise and regulated by PGC1- $\alpha$ [72] is secreted from the muscle into the blood and is another candidate for the browning of certain WAT depots, both in vitro and in vivo. Apparently, a modest elevation in irisin circulating levels leads to increased expression of several mitochondrial genes in white fat, increase in UCP1 expression levels and energy expenditure, reduction of fasting plasma insulin levels and improvement of glucose tolerance in mice fed a high fat diet, being regarded as a putative target to treat obesity and insulin resistance $[72,156]$. The transcriptional changes induced by irisin were addressed on a global scale using gene expression arrays in mouse [72]. It was shown that UCP1 and 3 others known brown fat genes, Elovl3, Cox7a and Otop1, were among the 8 most up-regulated genes, besides Prdm16 and PGC1- $\alpha$ that were also increased. Conversely, genes characteristic of white fat development were down regulated, such as leptin. These data strongly suggest the activation of browning and thermogenic genes by irisin. Nevertheless, irisin efficacy in browning WAT depots in humans is still under debate [157,158].

Fibroblast growth factor 21 (FGF21), expressed predominantly in liver, WAT, BAT and pancreas, has emerged as an important metabolic regulator that induces weight loss in obese mouse models through increases in energy expenditure without alterations in food intake $[159,160]$. FGF21 is considered the only known cold-induced secreted protein that functions to increase the appearance of brite adipocytes in WAT depots in an autocrine/paracrine manner, increasing the expression of thermogenic genes in fat tissues, partially via the enhancement adipose tissue PGC1-a protein level [159]. Therefore, FGF21 could be considered as a hormone that enhances $\beta$-oxidation and energy expenditure via WAT browning [123,158]. Although some authors claim that FGF21 metabolic effects are associated with raised UCP1 expression, a thermogenic protein located in the inner mitochondrial membrane, a recent study performed with UCP1 null mice shows otherwise [161]. In this study, it was verified that the anti-obesity action of FGF21 treatment, such as food intake reduction, glycemic control, reduced circulating cholesterol or free fatty acid levels and raised adiponectin levels, occurred independently of UCP1-dependent thermogenesis. Nevertheless, UCP1-dependent thermogenesis was required to reduce TAG levels and for the full magnitude of FGF21-induced elevation of energy expenditure in vivo [161]. Therefore, it seems that FGF21 have UCP1-dependent and UCP1-independent metabolic functions and more experiments should be carried out to elucidate these findings. We conclude that FGF21 induces UCP1 expression, but not always UCP1 and FGF21 have concerted actions.

Additionally, microRNAs are reported to trigger WAT browning. After cold exposure, miR-27 is downregulated in BAT and subcutaneous white adipose tissue and, besides, it is also downregulated during brown adipogenesis of primary pre-adipocytes in vitro [162]. MiR-27, which is supposed to target and silence PHBs [56], directly targets and negatively regulates the essential components of the brown transcriptional network [162]. Mori and cols [163] showed that miR-196a induces functional brown adipocytes in WAT through the suppression of Hoxc8, which functions as a gatekeeper of the inducible brown adipogenesis. Chen and cols (2013) demonstrated that the bistable loop involving microRNA 155 and C/EBP $\beta$ regulates the development of brown and beige fat cells. [164]. Another recent study [165] reported that miR-455 exhibits a BAT-specific expression pattern and is induced by cold and the browning inducer BMP7. Therefore, these studies suggest that microRNAs inhibition/super expression can be regarded as a novel therapeutic approach for metabolic diseases aiming at increasing the beige/brown fat mass (Table 4).

\begin{tabular}{|c|c|}
\hline Mitochondrial & Others \\
\hline Biogenesis & FGF21 \\
\hline PGC1- $\alpha, \beta$ & Prdm16 \\
\hline UCP1 & Cold \\
\hline FAO & $\beta$ adrenergic stimulation \\
\hline ATP (for FA reesterification) & Irisin (?) \\
\hline PHBs & MiR27, MiR196a, MiR455 \\
\hline MitoNEET & \\
\hline Mitophagy & \\
\hline
\end{tabular}

Table 4: WAT browning factors 
All in all, transdifferentiation and browning rely heavily on mitochondrial parameters (Figure 1) and they are promising pathways to increase whole body energy expenditure and the development of therapies to treat obesity and related diseases in humans. Research in this field of expertise is moving fast and, probably, the fruits of these studies will soon shed light on new clinical trials.

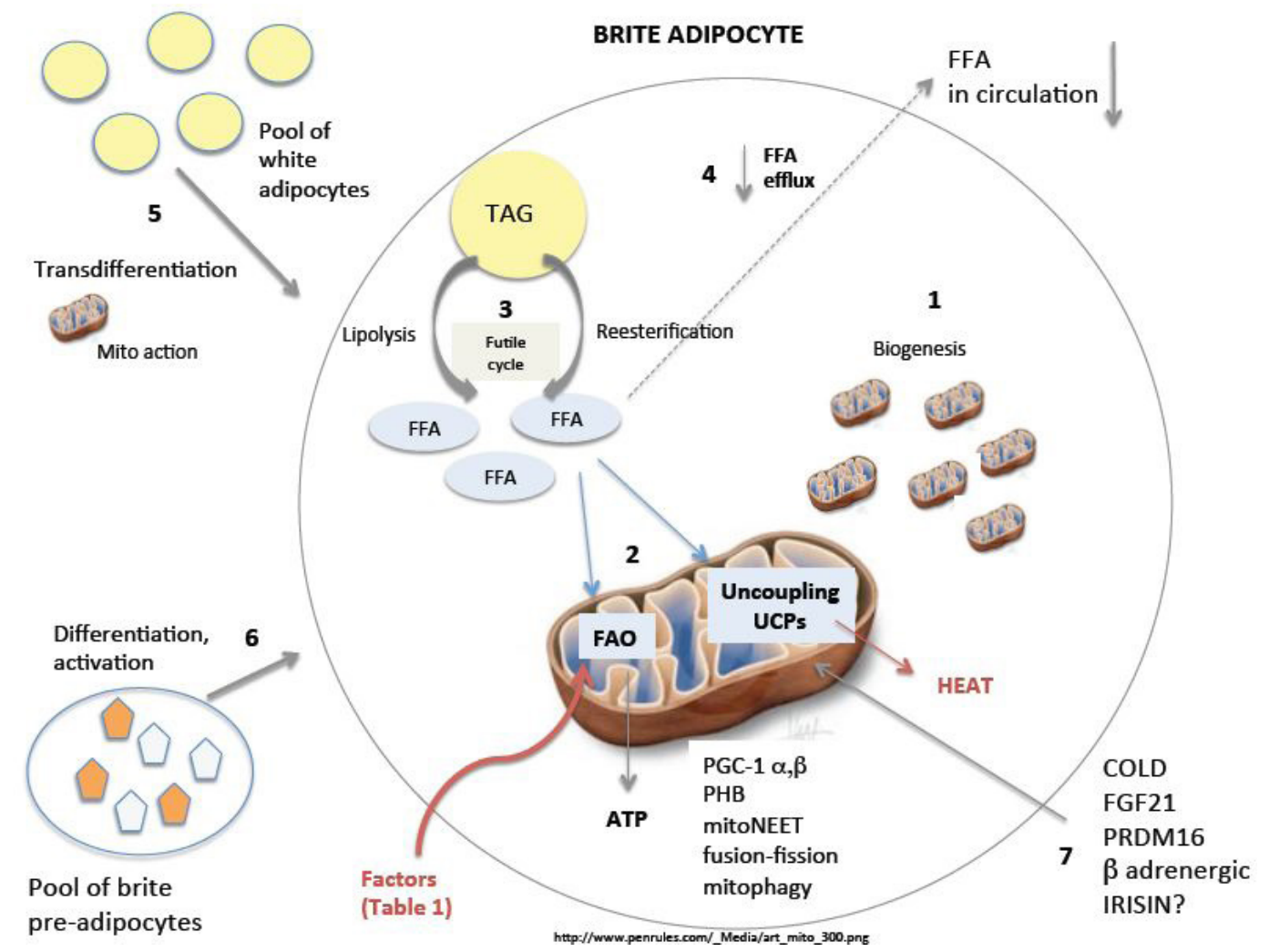

Figure 1: Mitochondrial actions (and other factors) for WAT browning and energy expenditure augmentation

Transdifferentiation (5): a pool of classical white adipocytes undergoes transdifferentiation into brite adipocytes. There is a brite adipocyte threshold variation among different fat depots. Mitochondria and other factors that induce transdifferentiation: PGC-1 $\alpha$ and $\beta$, related to mitochondrial biogenesis (1); PHBs; mitoNEET; fusion-fission; mitophagy; FAO and uncoupling by UCPs (2). FGF21, Prdm16 (7) and PGC1- $\alpha$, $\beta$ promote the raise of UCP1 levels, which is also activated by cold exposure and adrenergic stimuli (7), favoring uncoupling and thermogenesis. The combination of enhanced lipolysis and mitochondrial activity, such as FAO and/or uncoupling enhances WAT energy expenditure, reduces FFA release to circulation (4) and contributes to white adipocyte browning. In addition, FAO may contribute with ATP generation to feed the futile cycle (3), which is also responsible for augmented WAT energy expenditure. Altogether, the simultaneous activation of WAT lipolysis, mitochondrial FAO and the futile cycle, would shift WAT metabolism towards a higher oxidative (BAT-like) profile. (6) Pool of brite preadipocytes can differentiate into white and inactive brown adipocytes (pre-brite). Inactive brown adipocytes can be further activated by cold exposure, beta adrenergic stimulation, UCP1, Prdm16, FGF21, Irisin, mitochondria biogenesis and then become functional brite adipocytes (adapted from [153]).

\section{Concluding Remarks and Perspectives}

Here we highlight some key points of mitochondrial parameters that exert substantial contribution to white adipocyte metabolism, from proliferation and adipogenesis to energy balance. They include mitochondria biogenesis, mitophagy, dynamics, FAO and uncoupling.

There is a growing body of evidences indicating that mitochondrial oxidative metabolism may contribute to enhance WAT energy expenditure. We infer that compounds that accelerate lipolysis and boost mitochondria FAO would contribute to reduce circulating FFA as well as TAG levels, implicating in less lipotoxicity, insulin resistance and obesity. Unsaturated fatty acids are promising molecules for this purpose mainly because they may activate WAT PPAR- $\alpha$ which, in turn, activates lipolysis and FAO. However, the direct link between increased lipolysis and FAO in adipose tissue is not fully elucidated. We suggest that the simultaneous activation of WAT lipolysis and mitochondrial FAO would shift WAT metabolism towards a higher oxidative (BATlike) profile. Besides, lipolysis and lipogenesis taking place at similar rates (futile cycle) could synergize this process, leading to weight loss in a mid-long term.

WAT browning is also a promising pathway to improve WAT energy expenditure, where FFA would be a substrate for UCP1mediated mitochondrial uncoupling and heat generation instead of being stored as TAG. Nevertheless, this concept needs further clarification, including the elucidation of which WAT depots are more prone for browning and the confirmation (or not) of the existence of "brite" pre-adipocytes pool. 
Therefore, the investigation of WAT mitochondrial function (and dysfunction) is mandatory for a better understanding of WAT metabolism and, consequently, for the development of new therapies to improve insulin sensitivity, to treat obesity and related diseases.

\section{Acknowledgements}

Prof. Rui Curi (USP) for valuable discussions concerning this manuscript. FAPESP GRANTS: 2011/51701-3; 2012/10525-0; 2009/53964-1; 2011/51627-8.

\section{References}

1. Lottenberg SA, Glezer A, Turatti LA (2007) Metabolic syndrome: identifying the risk factors. J Pediatr 83: S204-8.

2. Reuters (2014) Weight of the world 2.1 billion people obese or overweight, USA.

3. Carrer M, Liu N, Grueter CE, Williams AH, Frisard MI, et al.(2012) Control of mitochondrial metabolism and systemic energy homeostasis by microRNAs 378 and 378*. Proc Natl Acad Sci USA 109: 15330-5.

4. Hernández-Aguilera A, Rull A, Rodríguez-Gallego E, Riera-Borrull M, Luciano-Mateo F, et al. (2013) Mitochondrial dysfunction: a basic mechanism in inflammation-related non-communicable diseases and therapeutic opportunities. Mediators Inflamm 10.1155/2013/135698.

5. Kusminski CM, Holland WL, Sun K, Lin Y, Askew GR, et al. (2012) MitoNEETdriven alterations in adipocyte mitochondrial activity reveal a crucial adaptative process that preserves insulin sensitivity in obesity. Nature Med 18: 1539-49.

6. Fernández-Sánchez A, Madrigal-Santillán E, Bautista M, Esquivel-Soto J, Morales-González A, et al. (2011) Inflammation, oxidative stress, and obesity. Int J Mol Sci 12: 3117-32.

7. Crossno JTJ, Majka SM, Grazia T, Gill RG, Klemm DJ (2006) Rosiglitazone promotes development of a novel adipocyte population from bone marrow-derived circulating progenitor cells. J Clin Invest 116: 3220-8.

8. Goldman SJ, Zhang Y, Jin S (2011) Autophagic degradation of mitochondria in white adipose tissue differentiation. Antioxid Redox Signal 14: 1971-8.

9. Hauner H (2004) The new concept of adipose tissue function. Physiol Behav 83: 653-8.

10. Kershaw EE, Flier JS (2004) Adipose tissue as an endocrine organ. J Clin Endocrinol Metab 89: 2548-56.

11. Rosen ED, Spiegelman BM (2006) Adipocytes as regulators of energy balance and glucose homeostasis. Nature 444: 847-53.

12. Sethi JK, Vidal-Puig AJ (2007) Thematic review series: adipocyte biology. Adipose tissue function and plasticity orchestrate nutritional adaptation. J Lipid Res 48: $1253-62$

13. Zhang Y, Goldman S, Baerga R, Zhao Y, Komatsu M, et al. (2009) Adipose-specific deletion of autophagy-related gene 7 (atg7) in mice reveals a role in adipogenesis. Proc Natl Acad Sci USA 106: 19860-5.

14. Oh DY, Olefsky JM (2010) Wnt fans the flames in obesity. Science 329: 397-8.

15. Virtue S, Vidal-Puig A (2010) Adipose tissue expandability, lipotoxicity and the Metabolic Syndrome - An allostatic perspective. Biochim Biophys Acta 1801: $338-49$.

16. Wronska A, Kmiec Z (2012) Structural and biochemical characteristics of various white adipose tissue depots. Acta Physiol 205: 194-208.

17. De Pauw A, Tejerina S, Raes M, Keijer J, Arnould T (2009) Mitochondrial (dys)function in adipocyte (de)differentiation and systemic metabolic alterations. Am J Pathol 175: 927-39.

18. Forner F, Kumar C, Luber CA, Fromme T, Klingenspor M, et al. (2009) Proteome differences between brown and white fat mitochondria reveal specialized metabolic functions. Cell Metab 10: 324-35.

19. Medina-Gómez G (2012) Mitochondria and endocrine function of adipose tissue. Best Pract Res Clin Endocrinol Metab 26: 791-804.

20. Maechler P, Wollheim CB (2001) Mitochondrial function in normal and diabetic beta-cells. Nature 414: 807-12.

21. Duchen MR, Szabadkai G (2010) Roles of mitochondria in human disease. Essays Biochem 47: 115-37.

22. Novak I (2012) Mitophagy: a complex mechanism of mitochondrial removal. Antioxid Redox Signal 17: 794-802.

23. Campello S, Scorrano L (2012) Mitochondrial shape changes: orchestrating cell pathophysiology. EMBO Rep 11: 678-84.

24. Duchen MR (2014) Roles of mitochondria in health and disease. Diabetes 53: S96-102.

25. Kowald A, Kirkwood TBL (2011) Evolution of the mitochondrial fusion-fission cycle and its role in aging. PNAS 108: 10237-42.

26. Chan DC (2006) Mitochondria: dynamic organelles in disease, aging, and development. Cell 125: 1241-52.

27. De Andrade PBM, Rubi B, Frigerio F, Van Den Ouweland JMW, Maassen JA, et al. (2006) Diabetes-associated mitochondrial DNA mutation A3243G impairs cellular metabolic pathways necessary for beta cell function. Diabetologia 49: 1816-26.

28. Corona JC, Duchen MR (2015) Impaired mitochondrial homeostasis and neurodegeneration: towards new therapeutic targets? J Bioenerg Biomembr 47: 89-99. 29. Vercesi AE, Castilho RF, Kowaltowski AJ, Oliveira HC (2007) Mitochondrial energy metabolism and redox state in dyslipidemias. IUBMB Life 59: 263-8.

30. Begriche K, Massart J, Robin MA, Borgne-Sanchez A, Fromenty B (2011) Drug-induced toxicity on mitochondria and lipid metabolism: mechanistic diversity and deleterious consequences for the liver. J Hepatol 54: 773-94.

31. Brandon M, Baldi P, Wallace DC (2006) Mitochondrial mutations in cancer. Oncogene 25: 4647-62.

32. Chatterjee A, Mambo E, Sidransky D (2006) Mitochondrial DNA mutations in human câncer. Oncogene 25: 4663-74.

33. Putignani L, Raffa S, Pescosolido R, Rizza T, Del Chierico F, et al. (2012) Preliminary evidences on mitochondrial injury and impaired oxidative metabolism in breast cancer. Mitochondrion 12: 363-9.

34. Bowling AC, Beal MF (1995) Bioenergetic and oxidative stress in neurodegenerative diseases. Life Sci 56: 1151-71. 
35. Filosto M, Scarpelli M, Cotelli MS, Vielmi V, Todeschini A, et al. (2011) The role of mitochondria in neurodegenerative diseases. J Neurol $258: 1763-74$.

36. Martin LJ (2011) Mitochondrial pathobiology in ALS. J Bioenerg Biomembr 43: 569-79.

37. Kerr DS (2013) Review of clinical trials for mitochondrial disorders: 1997-2012. Neurotherapeutics 10: 307-19.

38. Pitceathly RD, McFarland R (2014) Mitochondrial myopathies in adults and children: management and therapy development. Curr Opin Neurol 27: 576-82.

39. Carriere A, Fernandez Y, Rigoulet M, Penicaud L, Casteilla L (2003) Inhibition of preadipocyte proliferation by mitochondrial reactive oxygen species. FEBS Lett 550: 163-7.

40. Toh SY, Gong J, Du G, Li JZ, Yang S, et al. (2008) Up-regulation of mitochondrial activity and acquirement of brown adipose tissue-like property in the white adipose tissue of fsp27 deficient mice. PLoS One 3: 2890.

41. Tejerina S, De Pauw A, Vankoningsloo S, Houbion A, Renard P, et al. (2009) Mild mitochondrial uncoupling induces 3T3-L1 adipocyte de-differentiation by a PPAR $\gamma$-independent mechanism, whereas TNF $\alpha$-induced de differentiation is PPAR $\gamma$ dependent. J Cell Science 122: 145-55.

42. Tedesco L, Valerio A, Dossena M, Cardile A, Ragni M, et al. (2010) Cannabinoid receptor stimulation impairs mitochondrial biogenesis in mouse white adipose tissue, muscle, and liver: the role of eNOS, p38 MAPK, and AMPK pathways. Diabetes 59: 2826-36.

43. Bordicchia M, Liu D, Amri EZ, Ailhaud G, Dessì-Fulgheri P, et al. (2012) Cardiac natriuretic peptides act via p38 MAPK to induce the brown fat thermogenic program in mouse and human adipocytes. J Clin Invest 122: 1022-36.

44. Koponen T, Cerrada-Gimenez M, Pirinen E, Hohtola E, Paananen J, et al. (2012) The activation of hepatic and muscle polyamine catabolism improves glucose homeostasis. Amino Acids 42: 427-40.

45. Kusminski CM, Park J, Scherer PE (2014) MitoNEET-mediated effects on browning of white adipose tissue. Nat Commun 5: 10.1038/ncomms4962.

46. Schöttl T, Kappler L, Braun K, Fromme T, Klingenspor M (2015) Limited mitochondrial capacity of visceral versus subcutaneous white adipocytes in male C57BL/6N mice. Endocrinology 156: 923-33.

47. Deveaud C, Beauvoit B, Salin B, Schaeffer J, Rigoulet M (2014) Regional differences in oxidative capacity of rat white adipose tissue are linked to the mitochondrial content of mature adipocytes. Mol Cell Biochem 267: 157-66.

48. Flachs P, Rossmeisl M, Kuda O, Kopecky J (2013) Stimulation of mitochondrial oxidative capacity in white fat independent of UCP1: a key to lean phenotype. Biochim Biophys Acta 1831: 986-1003.

49. Wilson-Fritch L, Burkart A, Bell G, Mendelson K, Leszyk J, et al. (2003) Mitochondrial biogenesis and remodeling during adipogenesis and in response to the insulin sensitizer rosiglitazone. Mol Cell Biol 23: 1085-94

50. Granneman JG, Li P, Zhu Z, Lu Y (2005) Metabolic and cellular plasticity in white adipose tissue I: effects of beta3-adrenergic receptor activation. Am J Physiol Endocrinol Metab 289: E608-16.

51. Shen W, Liu K, Tian C, Yang L, Li X, et al. (2008) R-alpha-lipoic acid and acetyl-L-carnitine complementarily promote mitochondrial biogenesis in murine 3T3-L1 adipocytes. Diabetologia 51: 165-74.

52. Wilson-Fritch L, Nicoloro S, Chouinard M, Lazar MA, Chui PC, et al. (2004) Mitochondrial remodeling in adipose tissue associated with obesity and treatment with rosiglitazone. J Clin Invest 114: 1281-9.

53. Duivenvoorde LP, van Schothorst EM, Bunschoten A, Keijer J (2011) Dietary restriction of mice on a high-fat diet induces substrate efficiency and improves metabolic health. J Mol Endocrinol 47: 81-97.

54. Ntambi JM, Young-Cheul K (2000) Adipocyte differentiation and gene expression. J Nutr 130: 3122S-6S.

55. White UA, Stephens JM (2010) Transcriptional factors that promote formation of white adipose tissue. Mol Cell Endocrinol 318: 10-4.

56. Kang T, Lu W, Xu W, Anderson L, Bacanamwo M, et al. (2013) MicroRNA-27 (miR-27) targets prohibitin and impairs adipocyte differentiation and mitochondrial function in human adipose-derived stem cells. J Biol Chem 288: 34394-402.

57. Peng YT, Chen P, Ouyang RY, Song L (2015) Multifaceted role of prohibitin in cell survival and apoptosis. Apoptosis. 20: 1135-49.

58. Lourenço AB, Muñoz-Jiménez C, Venegas-Calerón M, Artal-Sanz M (2015) Analysis of the effect of the mitochondrial prohibitin complex, a context-dependent modulator of longevity, on the C. elegans metabolome. Biochim Biophys Acta 1847: 1457-68.

59. Osman C, Haag M, Potting C, Rodenfels J, Dip PV, et al. (2009) The genetic interactome of prohibitins: coordinated control of cardiolipin and phosphatidylethanolamine by conserved regulators in mitochondria. J Cell Biol 184: 583-96.

60. Liu D, Lin Y, Kang T, Huang B, Xu W, et al. (2012) Mitochondrial dysfunction and adipogenic reduction by prohibitin silencing in 3T3-L1 cells. PLoS One 7: 10.1371/journal.pone.0034315

61. Cho SY, Park PJ, Shin ES, Lee JH, Chang HK (2009) Proteomic analysis of mitochondrial proteins of basal and lipolytically (isoproterenol and TNF-alpha)stimulated adipocytes J Cell Biochem 106: 257-66.

62. Ande SR, Nguyen KH, Padilla-Meier GP, Wahida W, Nyomba BL, et al. (2014) Prohibitin overexpression in adipocytes induces mitochondrial biogenesis, leads to obesity development, and affects glucose homeostasis in a sex-specific manner. Diabetes 63: 3734-41.

63. Vessal M, Mishra S, Moulik S, Murphy LJ (2006) Prohibitin attenuates insulin-stimulated glucose and fatty acid oxidation in adipose tissue by inhibition of pyruvate carboxylase. FEBS J 273: 568-76.

64. Liang H, Ward WF (2006) PGC-1alpha: a key regulator of energy metabolism. Adv Physiol Educ 30: 145-51.

65. Alaynick WA (2008) Nuclear receptors, mitochondria and lipid metabolism. Mitochondrion 8: 329-37.

66. Rato L, Duarte AI, Tomás GD, Santos MS, Moreira PI, et al. (2014) Pre-diabetes alters testicular PGC1- $\alpha /$ SIRT3 axis modulating mitochondrial bioenergetics and oxidative stress. Biochim Biophys Acta 1837: 335-44.

67. Hondares E, Rosell M, Díaz-Delfín J, Olmos Y, Monsalve M, et al. (2011) Peroxisome proliferator-activated receptor a (PPAR $\alpha$ ) induces PPAR $\gamma$ coactivator 1a (PGC-1a) gene expression and contributes to thermogenic activation of brown fat: involvement of PRDM16. J Biol Chem 286: 43112-22.

68. Uldry M, Yang W, St-Pierre J, Lin J, Seale P, et al. (2006) Complementary action of the PGC-1 coactivators in mitochondrial biogenesis and brown fat differentiation. Cell Metab 3: 333-41.

69. Sonoda J, Mehl IR, Chong LW, Nofsinger RR, Evans RM (2007) PGC-1beta controls mitochondrial metabolism to modulate circadian activity, adaptive thermogenesis, and hepatic steatosis. Proc Natl Acad Sci 104: 5223-8. 
70. Bansode RR, Huang W, Roy SK, Mehta M, Mehta KD (2008) Protein kinase C deficiency increases fatty acid oxidation and reduces fat storage. J Biol Chem 283: 231-6.

71. Sutherland LN, Bomhof MR, Capozzi LC, Basaraba SAU, Wright DC (2009) Exercise and adrenaline increase PGC-1a mRNA expression in rat adipose tissue. J Physiol 587: 1607-17.

72. Boström P, Wu J, Jedrychowski MP, Korde A, Ye L, et al. (2012) A PGC1-a-dependent myokine that drives brown-fat-like development of white fat and thermogenesis. Nature 481: 463-8.

73. Gao CL, Liu GL, Liu S, Chen XH, Ji CB, et al. (2011) Overexpression of PGC-1 $\beta$ improves insulin sensitivity and mitochondrial function in 3T3-L1 adipocytes. Mol Cell Biochem 353: 215-23.

74. Deng T, Sieglaff DH, Zhang A, Lyon CJ, Ayers SD, et al. (2011) A peroxisome proliferator-activated receptor gamma (PPARgamma)/PPARgamma coactivator lbeta autoregulatory loop in adipocyte mitochondrial function. J Biol Chem. 286: 30723-31.

75. Enguix N, Pardo R, González A, López VM, Simó R, et al. (2013) Mice lacking PGC-1 $\beta$ in adipose tissues reveal a dissociation between mitochondrial dysfunction and insulin resistance. Molecular Metabolism 2: 215-26.

76. Harper RD, Saggerson ED (1976) Factors affecting fatty acid oxidation in fat cells isolated from rat white adipose tissue. J Lipid Res 17: 516-26.

77. Baht HS, Saggerson ED (1988) Comparison of triacylglycerol synthesis in rat brown and white adipocytes. Effects of hypothyroidism and streptozotocindiabetes on enzyme activities and metabolic fluxes. Biochem J 250: 325-33.

78. Reidy SP, Weber JM (2002) Accelerated substrate cycling: a new energy- wasting role for leptin in vivo. Am J Physiol Endocrinol Metab 282: E312-7.

79. Wolfe RR, Klein S, Carraro F, Weber JM (1990) Role of triglyceride-fatty acid cycle in controlling fat metabolism in humans during and after exercise. Am J Physiol Endocrinol Metab 258: E382-9.

80. Ho PW, Ho JW, Liu HF, So DH, Tse ZH, et al. (2012) Mitochondrial neuronal uncoupling proteins: a target for potential disease-modification in Parkinson's disease. Transl Neurodegener 1: 3 .

81. Chevillotte E, Giralt M, Miroux B, Ricquier D, Villarroya F (2007) Uncoupling protein-2 controls adiponectin gene expression in adipose tissue through the modulation of reactive oxygen species production. Diabetes 56: 1042-50.

82. Ducluzeau PH, Priou M, Weitheimer M, Flamment M, Duluc L, et al. (2011) Dynamic regulation of mitochondrial network and oxidative functions during 3T3-L1 fat cell differentiation. J Physiol Biochem 67: 285-96.

83. Maassen JA, Romijn JA, Heine RJ (2007) Fatty acid-induced mitochondrial uncoupling in adipocytes as a key protective factor against insulin resistance and beta cell dysfunction: a new concept in the pathogenesis of obesity-associated type 2 diabetes mellitus. Diabetologia 50: 2036-41.

84. Maassen JA, Romijn JA, Heine RJ (2008) Fatty acid-induced mitochondrial uncoupling in adipocytes as a key protective factor against insulin resistance and beta cell dysfunction: do adipocytes consume sufficient amounts of oxygen to oxidise fatty acids? Diabetologia 51: 907-8.

85. Vankoningsloo S, Piens M, Lecocq C, Gilson A, De Pauw A, et al. (2005) Mitochondrial dysfunction induces triacylglyceride accumulation in 3T3-L1 cells: role of fatty acid beta-oxidation and glucose. J Lipid Res 46: 1133-49.

86. Frayn KN, Langin D, Karpe F (2008) Fatty acid-induced mitochondrial uncoupling in adipocytes is not a promising target for treatment of insulin resistance unless adipocyte oxidative capacity is increased. Diabetologia 51: 394-7.

87. Böttcher H, Fürst P (1997) Decreased white fat cell thermogenesis in obese individuals. Int J Obes Relat Metab Disord 21: 439-44.

88. Flachs P, Horakova O, Brauner P, Rossmeisl M, Pecina P, et al. (2005) Polyunsaturated fatty acids of marine origin upregulate mitochondrial biogenesis and induce -oxidation in white fat. Diabetologia 48: 2365-75.

89. Heinonen S, Buzkova J, Muniandy M, Kaksonen R, Ollikainen M, et al. (2015) Impaired Mitochondrial Biogenesis in Adipose Tissue in Acquired Obesity. Diabetes 64: 3135-45.

90. Ahmadian M, Wang Y, Sul HS (2010) Lipolysis in adipocytes. Int J Biochem Cell Biol 42: 555-9.

91. Gaidhu MP, Frontini A, Hung S, Pistor K, Cinti S, et al. (2011) Chronic AMP-kinase activation with AICAR reduces adiposity by remodeling adipocyte metabolism and increasing leptin sensitivity. J Lipid Res 52: 1702-11.

92. Watt MJ, Spriet LL (2010) Triacylglycerol lipases and metabolic control: implications for health and disease. Am J Physiol Endocrinol Metab 299: E162-8.

93. Li P, Zhu Z, Lu Y, Granneman JG (2005) Metabolic and cellular plasticity in white adipose tissue II: role of peroxisome proliferator-activated receptor-alpha. Am J Physiol Endocrinol Metab 289: E617-26.

94. Barbatelli G, Murano I, Madsen L, Hao Q, Jimenez M, et al. (2010) The emergence of cold-induced brown adipocytes in mouse white fat depots is determined predominantly by white to brown adipocyte transdifferentiation. Am J Physiol Endocrinol Metab 298: E1244-53.

95. Landry AP, Ding H (2014) Redox control of human mitochondrial outer membrane protein MitoNEET [2Fe-2S] clusters by biological thiols and hydrogen peroxide. J Biol Chem 289: 4307-15.

96. Badman MK, Pissios P, Kennedy AR, Koukos G, Flier JS, et al. (2007) Hepatic fibroblast growth factor 21 is regulated by PPARalpha and is a key mediator of hepatic lipid metabolism in ketotic states. Cell Metab 5: 426-37.

97. Chartoumpekis DV, Habeos IG, Ziros PG, Psyrogiannis AI, Kyriazopoulou VE, et al. (2011) Brown adipose tissue responds to cold and adrenergic stimulation by induction of FGF21. Mol Med 17: 736-40.

98. Villarroya F, Iglesias R, Giralt M (2007) PPARs in the control of uncoupling proteins gene expression. PPAR Res 2007: 74364.

99. Mandard S, Müller M, Kersten S (2004) Peroxisome proliferator-activated receptor alpha target genes. Cell Mol Life Sci 61: $393-416$.

100. Colca JR, McDonald WG, Waldon DJ, Leone JW, Lull JM, et al. (2004) Identification of a novel mitochondrial protein (“mitoNEET”) cross-linked specifically by a thiazolidinedione photoprobe. Am J Physiol Endocrinol Metab 286: E252-60.

101. Bolsoni-Lopes A, Festuccia WT, Farias TS, Chimin P, Torres-Leal FL, et al. (2013) Palmitoleic acid (n-7) increases white adipocyte lipolysis and lipase content in a PPARa-dependent manner. Am J Physiol Endocrinol Metab 305: E1093-102.

102. Suárez J, Rivera P, Arrabal S, Crespillo A, Serrano A, et al. (2014) Oleoylethanolamide enhances $\beta$-adrenergic-mediated thermogenesis and white-to-brown adipocyte phenotype in epididymal white adipose tissue in rat. Dis Model Mech 7: 129-41.

103. Wan Z, Root-McCaig J, Castellani L, Kemp BE, Steinberg GR, et al. (2014) Evidence for the role of AMPK in regulating PGC-1 alpha expression and mitochondrial proteins in mouse epididymal adipose tissue. Obesity 22: 730-8. 
104. Lagouge M, Argmann C, Gerhart-Hines Z, Meziane H, Lerin C, et al. (2006) Resveratrol improves mitochondrial function and protects against metabolic disease by activating SIRT1 and PGC-1alpha. Cell 127: 1109-22.

105. Bordicchia M, Pocognoli A, D’Anzeo M, Siquini W, Minardi D, et al. (2014) Nebivolol induces, via $\beta 3$ adrenergic receptor, lipolysis, uncoupling protein 1, and reduction of lipid droplet size in human adipocytes. J Hypertens 32: 389-96.

106. Arikawa E, Ma RC, Isshiki K, Luptak I, He Z, et al. (2007) Effects of insulin replacements, inhibitors of angiotensin, and PKCbeta’s actions to normalize cardiac gene expression and fuel metabolism in diabetic rats. Diabetes 56: 1410-20.

107. Kumar A, Shiloach J, Betenbaugh MJ, Gallagher EJ (2015) The beta-3 adrenergic agonist (CL-316,243) restores the expression of down-regulated fatty acid oxidation genes in type 2 diabetic mice. Nutr Metab 12: 8.

108. Steffensen KR, Jakobsson T, Gustafsson JÅ (2013) Targeting liver X receptors in inflammation. Expert Opin Ther Targets 17: 977-90.

109. Peng D, Hiipakka RA, Xie JT, Dai Q, Kokontis JM, et al. (2011) A novel potent synthetic steroidal liver X receptor agonist lowers plasma cholesterol and triglycerides and reduces atherosclerosis in LDLR(-/-) mice. Br J Pharmacol 162: 1792-804.

110. Hernandez A, de Mena RM, Martin E, Obregon MJ (2011) Differences in the response of UCP1 mRNA to hormonal stimulation between rat and mouse primary cultures of brown adipocytes. Cell Physiol Biochem 28: 969-80.

111. Saito M, Okamatsu-Ogura Y, Matsushita M, Watanabe K, Yoneshiro T, et al. (2009) High incidence of metabolically active brown adipose tissue in healthy adult humans: effects of cold exposure and adiposity. Diabetes 58: 1526-31.

112. Sacco E, Bientinesi R (2012) Mirabegron: a review of recent data and its prospects in the management of overactive bladder.Ther Adv Urol 4: 315-24.

113. Cypess AM, Weiner LS, Roberts-Toler C, Franquet Elía E, Kessler SH, et al. (2015) Activation of human brown adipose tissue by a $\beta 3$-adrenergic receptor agonist. Cell Metab 21: 33-8.

114. Tuttle KR, McGill JB, Bastyr EJ, Poi KK, Shahri N, et al. (2015) Effect of ruboxistaurin on albuminuria and estimated GFR in people with diabetic peripheral neuropathy: results from a randomized trial. Am J Kidney Dis 65: 634-6.

115. Manrique C, Whaley-Connell A, Sowers JR (2009) Nebivolol in obese and non-obese hypertensive patients. J Clin Hypertens 11: 309-15.

116. Merchant N, Rahman ST, Ferdinand KC, Haque T, Umpierrez GE, et al. (2011) Effects of nebivolol in obese African Americans with hypertension (NOAAH): markers of inflammation and obesity in response to exercise-induced stress. J Hum Hypertens 25: 196-202.

117. Gul R, Mahmood A, Luck C, Lum-Naihe K, Alfadda AA, et al. (2015) Regulation of cardiac miR-208a, an inducer of obesity, by rapamycin and nebivolol. Obesity (Silver Spring) 23: 2251-9.

118. Kita T, Nishida H, Shibata H, Niimi S, Higuti T, et al. (2009) Possible role of mitochondrial remodelling on cellular triacylglycerol accumulation. J Biochem 146: 787-96.

119. Wang Y, Katayama A, Terami T, Han X, Nunoue T, et al. (2015) Translocase of inner mitochondrial membrane 44 alters the mitochondrial fusion and fission dynamics and protects from type 2 diabetes. Metabolism 64: 677-88.

120. Kubli DA, Gustafsson ÅB (2012) Mitochondria and mitophagy: the yin and yang of cell death control. Circ Res 111: 1208-21.

121. Kim I, Rodriguez-Enriquez S, Lemasters JJ (2007) Selective degradation of mitochondria by mitophagy. Arch Biochem Biophys 462: 245-53.

122. Figueira TR, Barros MH, Camargo AA, Castilho RF, Ferreira JC, et al. (2013) Mitochondria as a source of reactive oxygen and nitrogen species: from molecular mechanisms to human health. Antioxid Redox Signal 18: 2029-74.

123. Kim KH, Jeong YT, Oh H, Kim SH, Cho JM, et al. (2013) Autophagy deficiency leads to protection from obesity and insulin resistance by inducing Fgf21 as a mitokine. Nat Med 19: 83-92.

124. Youle RJ, Narendra DP (2011) Mechanisms of mitophagy. Nat Rev Mol Cell Biol 12: 9-14.

125. Zhang Y, Zeng X, Jin S (2012) Autophagy in adipose tissue biology. Pharmacol Res 66: 505-12.

126. Seale P, Conroe HM, Estall J, Kajimura S, Frontini A, et al. (2011) Prdm16 determines the thermogenic program of subcutaneous white adipose tissue in mice. J Clin Invest 121: 96-105.

127. Schulz TJ, Tseng YH (2013) Brown adipose tissue: development, metabolism and beyond. Biochem J 453: 167-78.

128. Nagase I, Yoshida T, Kumamoto K, Umekawa T, Sakane N, et al. (1996) Expression of uncoupling protein in skeletal muscle and white fat of obese mice treated with thermogenic beta 3-adrenergic agonist. J Clin Invest 97: 2898-904.

129. Lowell BB, Spiegelman BM (2000) Towards a molecular understanding of adaptive thermogenesis. Nature 404: 652-60.

130. Saito M, Okamatsu-Ogura Y, Matsushita M, Watanabe K, Yoneshiro T, et al. (2009) High incidence of metabolically active brown adipose tissue in healthy adult humans: effects of cold exposure and adiposity. Diabetes 58: 1526-31.

131. Yoneshiro T, Aita S, Matsushita M, Kameya T, Nakada K, et al. (2011) Brown adipose tissue, whole-body energy expenditure, and thermogenesis in healthy adult men. Obesity 19: 13-6.

132. Cypess AM, Lehman S, Williams G, Tal I, Rodman D, et al. (2009) Identification and importance of brown adipose tissue in adult humans. N Engl J Med 360: 1509-17.

133. Fedorenko A, Lishko PV, Kirichok Y (2012) Mechanism of fatty-acid-dependent UCP1 uncoupling in brown fat mitochondria. Cell 151: 400-13.

134. Seale P, Bjork B, Yang W, Kajimura S, Chin S, et al. (2008) PRDM16 controls a brown fat/skeletal muscle switch. Nature 454: 961-7.

135. Park A, Kim WK, Bae KH (2014) Distinction of white, beige and brown adipocytes derived from mesenchymal stem cells World J Stem Cells 6: 33-42.

136. Cannon B, Nedergaard J (2004) Brown adipose tissue: function and physiological significance. Physiol Rev 84: 277-359.

137. Nedergaard J, Bengtsson T, Cannon B (2007) Unexpected evidence for active brown adipose tissue in adult humans. Am J Physiol Endocrinol Metab 293: E444-52.

138. Gesta S, Tseng YH, Kahn CR (2007) Developmental origin of fat: tracking obesity to its source. Cell 131: 242-56.

139. van Marken Lichtenbelt WD, Vanhommerig JW, Smulders NM, Drossaerts JM, Kemerink GJ, et al. (2009) Cold-activated brown adipose tissue in healthy men. N Engl J Med 360: 1500-8.

140. Virtanen KA, Lidell ME, Orava J, Heglind M, Westergren R, et al. (2009) Functional brown adipose tissue in healthy adults. N Engl J Med 360: 1518-25. 
141. Saito M (2013) Brown adipose tissue as a regulator of energy expenditure and body fat in humans. Diabetes Metab J 37: $22-9$.

142. Cypess AM, Kahn CR (2010) Brown fat as a therapy for obesity and diabetes. Curr Opin Endocrinol Diabetes Obes 17: 143-9.

143. Whittle AJ, López M, Vidal-Puig A (2011) Using brown adipose tissue to treat obesity - the central issue. Trends Mol Med 17: 405-11.

144. Whittle AJ, Vidal-Puig A (2012) NPs heart hormones that regulate brown fat? J Clin Invest 122: 804-7.

145. Yoneshiro T, Aita S, Matsushita M, Kayahara T, Kameya T, et al. (2013) Recruited brown adipose tissue as an antiobesity agent in humans. J Clin Invest 123: 3404-8.

146. Vijgen GH, Bouvy ND, Teule GJ, Brans B, Schrauwen P, et al. (2011) Brown adipose tissue in morbidly obese subjects. PLoS One 6: e17247.

147. Lowell BB, S-Susulic V, Hamann A, Lawitts JA, Himms-Hagen J, et al. (1993) Development of obesity in transgenic mice after genetic ablation of brown adipose tissue. Nature 366: 740-2.

148. Yoneshiro T, Aita S, Matsushita M, Kayahara T, Kameya T, et al. (2013) Recruited brown adipose tissue as an antiobesity agent in humans. J Clin Invest 123: 3404-8.

149. Tran KV, Gealekman O, Frontini A, Zingaretti MC, Morroni M, et al. (2012) The vascular endothelium of the adipose tissue gives rise to both white and brown fat cells. Cell Metab 15: 222-9.

150. Petrovic N, Walden TB, Shabalina IG, Timmons JA, Cannon B, et al. (2010) Chronic peroxisome proliferator-activated receptor gamma (PPARgamma) activation of epididymally derived white adipocyte cultures reveals a population of thermogenically competent, UCP1-containing adipocytes molecularly distinct from classic brown adipocytes. J Biol Chem 285: 7153-64.

151. Smorlesi A, Frontini A, Giordano A, Cinti S (2012) The adipose organ: white-brown adipocyte plasticity and metabolic inflammation. Obes Rev13 Suppl 2: 83-96.

152. Rosenwald M, Wolfrum C (2014) The origin and definition of brite versus white and classical brown adipocytes. Adipocyte 3: 4-9.

153. Farmer SR (2008) Brown fat and skeletal muscle: unikely cousins? Cell 134: 726-7.

154. Campioli E, Carnevale G, Avallone R, Guerra D, Baraldi M (2011) Morphological and receptorial changes in the epididymal adipose tissue of rats subjected to a stressful stimulus. Obesity 19: 703-8.

155. Fisher FM, Kleiner S, Douris N, Fox EC, Mepani RJ, et al. (2012) FGF21 regulates PGC-1a and browning of white adipose tissues in adaptive thermogenesis Genes Dev 26: 271-81.

156. Villarroya F (2012) Irisin, turning up the heat. Cell Metab15: 277-8.

157. Elsen M, Raschke S, Eckel J (2014) Browning of white fat: does irisin play a role in humans? J Endocrinol 222: R25-38.

158. Lee P, Linderman JD, Smith S, Brychta RJ, Wang J, et al. (2014) Irisin and FGF21 are cold-induced endocrine activators of brown fat function in humans. Cell Metab 19: 302-9.

159. Fisher FM, Kleiner S, Douris N, Fox EC, Mepani RJ, et al. (2012) FGF21 regulates PGC-1 $\alpha$ and browning of white adipose tissues in adaptive thermogenesis. Genes Dev 26: 271-81.

160. Véniant MM, Hale C, Helmering J, Chen MM, Stanislaus S, et al. (2012) FGF21 promotes metabolic homeostasis via white adipose and leptin in mice. PLoS One 7: e40164.

161. Samms RJ, Smith DP, Cheng CC, Antonellis PP, Perfield JW, et al. (2015) Discrete Aspects of FGF21 In Vivo Pharmacology Do Not Require UCP1. Cell Rep 11: $991-9$.

162. Sun L, Trajkovski M (2014) MiR-27 orchestrates the transcriptional regulation of brown adipogenesis. Metabolism 63: $272-82$.

163. Mori M, Nakagami H, Rodriguez-Araujo G, Nimura K, Kaneda Y (2012) Essential role for miR-196a in brown adipogenesis of white fat progenitor cells. PLoS Biol 10: e1001314.

164. Chen Y, Siegel F, Kipschull S, Haas B, Fröhlich H, et al. (2013) miR-155 regulates differentiation of brown and beige adipocytes via a bistable circuit. Nat Commun 4: 1769.

165. Zhang H, Guan M, Townsend KL, Huang TL, An D, et al. (2015) MicroRNA-455 regulates brown adipogenesis via a novel HIF1an-AMPK-PGC1a signaling network. EMBO Rep 16: 1378-93. 